\title{
Social Objects Without Intentions
}

\author{
BRIAN EPSTEIN
}

in Institutions, Emotions, and Group Agents:

Contributions to Social Ontology, edited by Anita

Konzelmann Ziv and Hans Bernhard Schmid.

Dordrecht: Springer, 2013.

It is often seen as a truism that social objects and facts are the product of human intentions. I argue that the role of intentions in social ontology is commonly overestimated. I introduce a distinction that is implicit in much discussion of social ontology, but is often overlooked: between a social entity's “grounds" and its "anchors." For both, I argue that intentions, either individual or collective, are less essential than many theorists have assumed. Instead, I propose a more worldly - and less intellectualist-approach to social ontology.

It is often seen as a truism that social objects (such as dollars) and social facts (such as that the Federal Reserve is raising interest rates) are the product of human intentions. As distinct from natural objects and facts, which exist or are the case independently of us, social objects and facts exist in virtue of our having attitudes toward the world, attitudes usually taken with some practical aim in mind.

This postulate is a basic building-block of prevailing theories of social ontology. Lynne Baker, for instance, explains that artifacts "are objects intentionally made to serve a given purpose."1 On John Searle’s view, institutional facts are created and maintained by collective attitudes:

\footnotetext{
${ }^{1}$ Baker 2004, p. 99.
} 
Collective intentionality assigns a new status to some phenomenon, where that status has an accompanying function that cannot be performed solely in virtue of the intrinsic physical features of the phenomenon in question. This assignment creates a new fact, an institutional fact, a new fact created by human agreement. ${ }^{2}$

My aim in this paper is to argue that focusing on intentions and attitudes distorts our understanding of social ontology. In some sense, it is surely correct that social entities ${ }^{3}$ partly depend on people, society, and human intentionality - otherwise, they would not be "social" at all. However, the role of intentions and other attitudes is often overestimated, making prevailing views excessively intellectualist. And it is especially misleading to approach social ontology as if it were a subfield of collective intentionality in particular, an approach that seems to be gaining momentum nowadays.

I begin by introducing a distinction that is implicit in much discussion of social ontology, but is often overlooked: the distinction between what I will call a social entity's "grounds" and its "anchors." Subsequently I discuss the role and limits of intentions in each of the two, respectively. I argue that many social entities have entirely non-intentional grounds. I further argue that the role of intentions in anchoring is less central than many theorists have assumed. Instead, I propose a more worldly - and less intellectualist approach to social ontology.

\section{Grounds and anchors: The intuitive distinction}

The project of social ontology is built on the observation that social facts are not "brute" facts in nature. The fact that Tufts is a university, that the Federal Reserve is raising interest rates, that the word 'Aristotle' refers to Aristotle, and that Mario Batali is a restauranteur, are all the case - at least in part - in virtue of various facts about people. Theories of social ontology

\footnotetext{
${ }^{2}$ Searle 1995, p. 46.

${ }^{3}$ I will use "entity" to avoid the tedious repetition of "facts or objects," where it is sufficiently unambiguous.
} 
identify, implicitly or explicitly, some cohesive set of social facts or objects such as "institutional facts," "semantic facts," "artifacts," etc. For that set, they work to provide an account of the other facts in virtue of which social facts are the case, or in virtue of which social objects exist.

Consider a particular institutional fact. For instance, take the dollar bill I am currently holding. For convenience, we can assign it a name, such as 'B23846598B' (in honor of its serial number). An example of an institutional fact, then, is: $B 23846598 B$ is a dollar. Let us call this fact ' $F$ '. We notice that $\mathrm{F}$ is not a fundamental or brute fact in nature, and therefore ask in virtue of which other facts - which more basic facts - is F the case.

In prevailing theories of social ontology, there are two different sorts of answers given to such questions. Consider, for instance, John Searle's account of institutional facts. ${ }^{4}$ Searle takes institutional facts such as F to hold in virtue of "constitutive rules" being in place in a context.

In Searle's account, the first answer to the question, In virtue of what is $F$ the case? is given within the constitutive rule for dollars. Searle says that this constitutive rule is:

(1) Bills issued by the Bureau of Engraving and Printing count as dollars in the United States. ${ }^{5}$

The first answer is then that the antecedent clause (what Searle calls the $\mathrm{X}$-term), is satisfied by the object in question. In other words, Searle's view is that the fact that grounds F is simply that B23846598B is a bill issued by the Bureau of Engraving and Printing. ${ }^{6}$

\footnotetext{
${ }^{4}$ Searle 1995, 2010.

${ }^{5}$ Searle 1995, p. 28.

${ }^{6}$ Searle gives slightly more detailed X-conditions in Searle 1995: 45-56. But this is the explicit constitutive rule he gives, and it is fine for our purposes. In the next sections of this paper, I point out that none of Searle's proposals give plausible X-conditions for dollars, but for the moment I am concerned with clarifying the form of constitutive rules. I use the term 'ground', following Fine 2001, Correia 2005, and others. Grounding is usually understood as holding between sets of facts. But we can also speak of objects, as well as facts, having grounds. A natural way to understand this is to take the grounds of
} 
This answer, of course, is incomplete, unless we also explain in virtue of what the constitutive rule itself is in place. Searle's answer to this is a second sort of fact. Constitutive rules are put in place, Searle argues, by our collective acceptance of them. It is in virtue of intentional states of a specific type being realized (i.e., the collective acceptance of a constitutive rule), that the constitutive rule is in place in the context. Thus the second answer given by Searle ${ }^{7}$ is that the constitutive rule (1) is in place in the United States in virtue of a fact of the form:

(2) People in the U.S. collectively accept rule (1).

A useful way to look at the difference between (1) and (2) is this: the former has the job of giving the conditions an object must satisfy in order to be a dollar, while the latter has the job of giving the facts that put those satisfaction conditions in place. The facts expressed by (2) are thus not the grounds for F itself, but what I will call F's “anchors.” They are what makes it the case that (1) is in place in the context.

This distinction is a crucial one. There are two very different roles for intentions and other factors in various accounts of social ontology. Some theorists take social facts and objects to have intentional grounds, while others take them to have intentional anchors. The considerations for evaluating these two claims will be quite different from one another.

\section{Refining the understanding of constitutive rules}

Using Searle's own formula for "constitutive rules" makes it difficult to avoid collapsing grounds and anchors into one another. In this section, I refine the notion of a constitutive rule, so as to clarify the two different questions I will address separately in the remainder of this paper: Must the grounds for social entities involve intentions? Must the anchors for

an object, such as the Federal Reserve, to be the grounds of the fact The Federal Reserve exists.

7 This general approach is endorsed by others, including Tuomela 2002 and Hindriks 2008. I discuss Tuomela's more nuanced views below. 
constitutive rules for social entities involve intentions? The constitutive rule is best understood as articulating what the grounds are for a social fact like F. Given that it has been anchored - however it has been anchored - the constitutive rule articulates a given set of grounding conditions within the domain where the rule is in place.

Several commentators have pointed out that Searle's "constitutive rule" formula has problems. Frank Hindriks, for instance, points out that that is unclear what work is done by Searle's “counts as” relation, beyond redundantly marking that the rule is collectively accepted. ${ }^{8}$ Amie Thomasson observes that there is an unresolved type/token ambiguity in Searle's rule and correspondingly in his treatment of the "self-referentiality" of institutional facts. For instance, it is left unclear whether that account takes us to have collective intentions toward each particular dollar, or toward dollars in general. To remedy this, Thomasson applies Kendall Walton's discussion of "principles of generation" 9 to distinguish three kinds of rules, with the following forms:

(3) Singular rules: (Of $a$ ) We collectively accept: Ya (where "Y" names a social feature)

(4) General rules: For all z, we collectively accept that (if $z$ meets all conditions in $\mathrm{X}$, then $\mathrm{Yz})^{10}$

(5) Existential rules: We collectively accept that (if all conditions $\mathrm{X}$ obtain, then there is some $\mathrm{z}$ such that $\mathrm{Yz}){ }^{11}$

It is useful to notice the inadequacy of Searle's formula in these ways, but Thomasson's rules do not fix the problem. First, although Thomasson is

\footnotetext{
${ }^{8}$ Hindriks 2008, p. 134.

${ }^{9}$ Walton 1990, p. $138 f f$.

${ }^{10}$ This formula should be changed, if it is to do what Thomasson wants. As stated, the rule requires that we have collective attitudes toward every object in the domain, which she wants to deny. It should instead be: We collectively accept that (for all z: if z meets all conditions in $\mathrm{X}$, then $\mathrm{Yz}$ ).

${ }^{11}$ Thomasson 2003, pp. 274-5.
} 
correct that Searle's formulation involves a type/token ambiguity, her singular rules are otiose. The reason is that (3) can be treated as a special case of (4), so long as the X-conditions can include object-dependent properties like being B23846598B.

Second, by stating the existential rule as Thomasson does, we lose a basic insight. It is true that the existential rule includes something that the general rule leaves out: that what is done by satisfying the appropriate conditions is that a dollar comes to exist. However, what the existential rule says is only that some object is created such that it is a dollar. It misses out the point that this bill is a dollar. ${ }^{12}$

But the most critical problem with Thomasson's rules is that they collapse the intuitive distinction I mentioned above. Even more overtly than Searle's rule does, these formulas include the collective acceptance of the rule as part of the rule. Hence they mix two very different sets of facts: those serving as the grounds for a social fact like F, and those facts in virtue of which the grounds for $\mathrm{F}$ are what they are; i.e., the facts that serve as the anchors of F. Instead, the constitutive rule is best understood as articulating what the grounds are for a social fact like F. Given that it has been anchored however it has been anchored - the constitutive rule articulates a given set of grounding conditions within the domain where the rule is in place.

It is useful, if we are to formulate the general fact more precisely, to employ the twin notions of "material constitution" and "coincident objects." The use of "coincidence” may taken seriously metaphysically, or it may just be regarded as an accounting trick, to keep track of the difference between such things as the paper and the dollar. Altogether, a better formulation of constitutive rules is:

(6) For all objects $\mathrm{z}$, if $\mathrm{z}$ is $\mathrm{X}$ then there is an object $\mathrm{u}$ such that $\mathrm{z}$ constitutes $\mathrm{u}$ and $\mathrm{u}$ is $\mathrm{Y}$,

\footnotetext{
12 This could be taken care of with the correct general rule, taken in tandem with this existential rule. Overall, Thomasson is correct to separate general rules from constitutive rules: there are many other facts about social entities that must be grounded, apart from facts about their existence and constitution.
} 
where $\mathrm{X}$ is the set of sufficient conditions the grounds must satisfy, in order for there to be a coinciding object having property $\mathrm{Y}^{13}$

Applying this to dollars (and using Searle’s conditions for being a dollar), we get:

(7) For all objects $\mathrm{z}$, if $\mathrm{z}$ is a bill issued by the Bureau of Engraving and Printing, then there is an object $\mathrm{u}$ such that $\mathrm{z}$ constitutes $\mathrm{u}$ and $\mathrm{u}$ is a dollar.

Here, the ground is the fact $z$ is a bill issued by the Bureau of Engraving and Printing. The relationships among the institutional fact, the constitutive rule (with the "X-conditions" on grounds in bold), and the fact's anchors are depicted in figure 1.

Anchoring the frame

In the frame

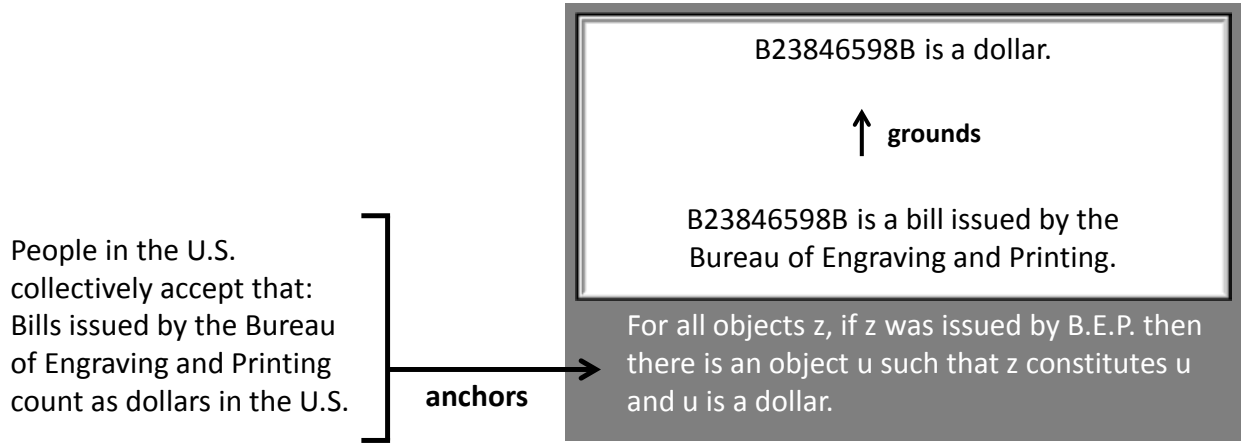

Figure 1

Searle's formula for constitutive rules obscures this picture. The formula "X counts as $\mathrm{Y}$ in C" makes it appear that both the grounds and anchors are

${ }^{13}$ I have left out the "context" parameter as well. If it is appropriate for some sort of object, a contextual restriction can always be included among the generation conditions. But I see no reason to assume that, for a community, a constitutive rule must only apply to objects in the context of the community in question. I discuss this below (in connection with "cowrie money"). This also differs from Hindriks' formalization; cf. Hindriks 2008, p. 134n42. 
facts that have to be in place in a context, in order for an institutional fact to be the case. But grounds and anchors play different roles. The anchors for a constitutive rule set up the conditions for something to be a dollar, restaurant, or university. With the constitutive rule in place, we can see what satisfies its $\mathrm{X}$-conditions in the actual context. Or we can look around at other contexts even other possible contexts - to see what things would satisfy the Xconditions in those contexts. I will discuss this further below, in connection with "cowrie-money," which is a monetary instrument whose X-conditions are simply being a shell of the snail Cypraea moneta.

Clarifying the constitutive rule allows us to formulate the questions about the role of intention in grounding and anchoring social entities. If we take as a starting point a particular class of social entities $S$, there are two distinct questions the social ontologist may investigate with respect to $\mathrm{S}$ :

(8) What sorts of facts are the grounds for Ss? That is, what properties figure into the X-conditions in the constitutive rules for Ss?

(9) What sorts of facts are the anchors for constitutive rules for Ss?

Questions about the role of intentions are simply sub-questions of (8) and (9):

(10) Must (or can) the grounds for Ss include (only or some) intentional properties?

(11) Must (or can) the anchors for constitutive rules for Ss involve (only or some) intentional facts?

Different theorists implicitly disagree on where to place intentions, in answer to these questions. While Searle and Baker, for instance, agree that intentions are central to social ontology, they disagree on where they figure in. Baker argues that for an object to be a boat, it must be produced intentionally by a maker, to serve some function. ${ }^{14}$ Among the necessary conditions for being a boat - i.e., among the grounds - are the functional intentions of its maker. Searle, on the other hand, argues that institutional facts often have brute facts as their "X-terms." That is, they have non-

${ }^{14}$ Baker 2004, p. 101. 
intentional grounds. He, however, holds that anchors are facts of a specific type: facts about the collective acceptance of the constitutive rule itself.

These roles, while easily confused, are distinct. In assessing the claim that social objects and facts are the product of human intentions, (10) and (11) can and should be evaluated separately.

\section{Must grounds for social entities involve intentions?}

In answer to question (10), it is straightforward to see that the grounds for institutional facts do not need to involve intentions at all. I will give a couple of cases.

One institutional fact Searle talks about is being a murderer. ${ }^{15}$ In our community, along with that status come appropriate punishments. To see that some institutional facts have intentional X-conditions while others have nonintentional X-conditions, compare being a murderer to being an involuntarymanslaughterer. ${ }^{16}$ Murder is the killing of another person with "malice aforethought," i.e., with a particular kind of intention. Thus the X-conditions for being a murderer involve intentions: killing another person with malice aforethought. Involuntary manslaughter, on the other hand, is distinguished from murder and voluntary manslaughter by being performed without an intention to kill (or perhaps without any intention at all). The X-conditions for being an involuntary-manslaughterer are devoid of intentions.

Turning to the case of dollars, matters are much more complicated than much of the social ontology literature seems to notice. Searle's own quick account, for instance, is contradictory. On the one hand, Searle argues that the "X-term" is a brute fact:

All sorts of things can be money, but there has to be some physical realization, some brute fact - even if it is only a bit of

\footnotetext{
${ }^{15}$ Searle 1995, p. 50.

${ }^{16}$ Voluntary manslaughter is either killing with malice aforethought but with mitigating circumstances, or else killing with a different intention - to cause bodily harm but not to kill.
} 
paper or a blip on a computer disk - on which we can impose the institutional form of status function. ${ }^{17}$

But Searle's own analysis does not treat the X-term for dollars as brute or non-intentional. Consider, for instance, what it takes for something to be "issued by the Bureau of Engraving and Printing." Plausibly, among the conditions for a bill to be "issued" by an institution requires that a person have had an intention of some sort in doing the issuance. This would make the grounds intentional, not brute.

Indeed, if the grounds for dollars include being issued by the Bureau of Engraving and Printing, there are two places where intentions may be implicitly part of these conditions. While not every individual bill is plausibly a product of a specific object-directed intention, there is plausibly a “derivative" or "implicit" intention to print each bill by the person who turns on the press, or by the person authorizing that the bill be printed. Moreover, the Bureau of Engraving and Printing itself has intentional existence conditions. So if this is the correct analysis of the generation conditions for dollars, then dollars are more like murder than manslaughter in this respect. ${ }^{18}$

On the other hand, other monetary instruments have strictly nonintentional grounds. One of the most widely used currencies in history is the cowrie shell. Societies that use cowrie shells as money merely collect them. They do not manufacture them, process them through a mint or central bank, or imprint markings into them. Given whatever anchors it takes to institute cowrie shells as currency in the domain, the conditions for a particular cowrie

\footnotetext{
${ }^{17}$ Searle 1995, p. 56. One consideration that puts pressure on this is the question of "freestanding Y-terms." Cf. Smith 2003. Searle responds to this challenge in Searle 2010 by replacing pieces of paper and blips in the "X-term" position with human mental states. I discuss this further below.

${ }^{18}$ One way of addressing the dependence of the Bureau of Engraving and Printing on intention may be, as Searle does, to introduce iterated constitutive rules. But the other cases I've mentioned, such as the intentional requirements for issuance, or for murder, are not treatable in this way.
} 
shell to be a piece of what we might call "C-money" are simply that it is a shell of the snail Cypraea moneta.

How can the grounds for being a piece of C-money only involve facts about snail shells? Surely a shell would not be a piece of C-money were it not the case that the facts anchoring the constitutive rule were also the case? Here we must be careful about how to evaluate such counterfactuals. The anchors set up the constitutive rule - that is, they set up the exhaustive conditions for what it takes to be a piece of C-money. The anchors are not themselves among these conditions, and for the purposes of evaluating ordinary counterfactuals are irrelevant. This can be seen by considering how being a piece of C-money would be applied across different circumstances. Given that the person assessing these circumstances has the anchors in place for her, she can identify C-money even outside her own context. For a $19^{\text {th }}$ century West African treasure hunter, for instance, it would have been perfectly correct to map out the deposits of C-money lying uncollected at the bottom of the sea. Or to dream of a planet made up only of C-money. The anchors put in place the conditions for something to be a piece of C-money. But the instantiation of the property being a piece of C-money only require satisfaction of the grounds. In the treasure hunter's dream, where she stands alone on the planet made entirely of Cypraea moneta shells, she is rich. This fact, of course, depends on the treasure hunter assessing that dream from the framework in which the constitutive rule for cowrie-money is anchored as it is. But the facts that anchor that framework should not be confused with the facts that ground the institutional fact.

As for artifacts, the most explicit claims that grounds for social entities must involve intentions arise in discussions of artifacts and artifactual kinds. Thomasson, for instance, says: "an artifactual kind term will pick out entities that are the products of largely successful intentions to create something of that kind (where that intention must involve a substantive, and substantively correct, conception of what features are relevant to being a member of the 
kind)."19 For an object to be an artifact of kind K, on this characterization, it must be the product of a largely successful intention to produce something of kind $\mathrm{K}$.

Now, Thomasson does distinguish artifacts from social entities. But the difference between the two is that artifacts are less demanding: "Unlike social and institutional objects, the existence of artifacts doesn't seem to presuppose any collective intentions of any kind-it makes perfect sense to suppose that a solitary human could create a knife, though not a government or money."20 On Thomasson's conception, the grounds for an artifact involve individual intentions, and those for a social entity involve collective intentions. Thus according to Thomasson, institutional facts have more stringent grounding conditions than artifacts. In her view, artifacts are intentionally grounded, while institutional facts are grounded in collective intentions. This suggests that if institutional facts do not need to be intentionally grounded, a fortiori artifacts do not either.

There are other reasons as well for suspecting that theorists have gone too far, when they insist that grounds for artifacts must involve intentions. Some artifacts do have intentional grounds. Above I pointed out that institutional entities like dollar bills and murderers have intentional grounds. Likewise, it may be that an artifact like a screwdriver does as well. For instance, it may be that screwdriver is a "Proper Function" kind. ${ }^{21}$ On this analysis, for an object to be a screwdriver it must have been designed or manufactured with the intention that it be usable for turning screws. Ruth Millikan and others have convincingly argued that both in biology and the social world, there are certain explanatory kinds that are plausibly "teleonomic."22 Historical factors, including the fact of being intentionally produced to perform a function, can be among the grounding conditions for an entity.

\footnotetext{
19 Thomasson 2007, p. 60.

20 Thomasson 2007, p. 52.

${ }^{21}$ Cf. Baker 2004; Millikan 1984.

${ }^{22}$ Millikan 1999.
} 
In biology, however, it has become clear in recent years that not all biological kinds are teleonomic. As Peter Godfrey-Smith notes, in biology we have to be pluralists about functions; functional kinds such as camouflage and swimming are far more plausibly interpreted as causal-role functions rather than as teleonomic ones. ${ }^{23}$ The Baker-Thomasson view that artifacts must be intentionally grounded implicitly denies that any artifact kinds are causal-role functional kinds. Baker insists that for an object to be a boat, a chair, a cup, and so on, it is insufficient that it satisfy the causal-role conditions we would expect boats, chairs, and cups to have. If GodfreySmith is correct, then to be a member of the kind swimmer requires only the satisfaction of a causal role. But for something to be a member of the kind boat requires that it have been produced intentionally. It is not clear what could justify such a sweeping restriction on the grounds for membership in artifact kinds. And if there were, that would imply a strange asymmetry between the conditions for being an institutional entity, which need not involve intentions, and those for being an artifact.

\section{Must anchors for constitutive rules involve intentions?}

A separate question is whether individual or collective intentions are required for anchoring the constitutive rule for a social or institutional fact. Many theorists will accept that grounds may be either intentional, nonintentional, or hybrid properties, but will claim that where collective intentions are required is in the facts that make the grounds what they are. Here I will not argue as definitively against a role for intention. I will, however, argue that prevailing theories have an overly stringent and intellectualist conception of the attitudes requires for anchoring constitutive rules. In particular, I aim to cast doubt on the claim that constitutive rules for social entities are anchored in collective intentions, and indeed, to cast doubt on the claim that there is any single sort of fact that is required for anchoring the social world. Instead, the world of social entities is a diverse one, with a

${ }^{23}$ Godfrey-Smith 1996, p. 23. 
variety of types of facts figuring into determining that constitutive rules are in place for a community.

If we brainstorm on kinds of facts that might serve to anchor a constitutive rule for some social entity $\mathrm{Y}$, it is easy to come up with a long list of candidates. Without attempting to be at all exhaustive, here are a few candidates roughly in order, from the most stringently intentional or intellectualized to the least:

(A1) Explicit collective agreement regarding what it takes to be a Y

(A2) Collective acceptance of the constitutive rule for $Y$

(A3) Collective acceptance of something other than a constitutive rule for $\mathrm{Y}$

(A4) Widespread common (but not collective) intentions toward $Y$

(A5) Intentions of one or a few individuals toward $\mathrm{Y}$, with practices spread by intentional reproduction

(A6) Intentions of one or a few individuals toward Y, with practices spread by mere causal transmission

(A7) Patterns or regularities in practices

and so on.

To place Searle on this continuum, he does not insist that facts of type (A1) are required for anchoring a constitutive rule, since explicit agreement is unnecessary. He does, however, require that the facts be at least of type (A2). ${ }^{24}$

There is, of course, a large historical literature that has weighed a range of these candidates for an analogous problem: namely, the analysis of convention. Theories of convention - at least reductive ones, such as Lewis's - mean to give the anchors for a convention to be in place in a community. ${ }^{25}$

\footnotetext{
${ }^{24}$ In Searle 2010, he changes his terminology from "collective acceptance" to "collective recognition." His notion of collective recognition seems to be close to Tuomela's notion of collective acceptance, inasmuch as it does not entail belief. I discuss collective acceptance below.

${ }^{25}$ Lewis 1969. They do not, of course, use the term 'anchor'.
} 
Interestingly, the literature on convention long took it as a given that conventions were products of agreement, explicit or tacit. This seems to have been the default view, perhaps from as early as Plato and Aristotle's discussions of the conventions of law and language at least until early modern treatments of the same topics. ${ }^{26}$ Only with Hume's analysis of convention did theorists start considering candidates lower down the list from something like (A2), lowering the explicit and cognitive demands for a convention to be in place. ${ }^{27}$

Lewis's account of convention, for instance, proposes that various beliefs, preferences, knowledge, facts about regularities, and facts about alternatives, combine to anchor the presence of a convention. Attitudes are required, but not attitudes towards the convention itself. According to Lewis, a convention is a regularity satisfying certain conditions. If the regularity failed to satisfy those conditions, it would not be a convention. The attitudes of the agents are attitudes toward the regularity (or to the solution of a coordination problem), not attitudes toward the convention. Another interesting feature of Lewis's account is that attitudes are not enough for anchoring a convention. His conditions include not only intentional ones, but also material facts about there being a regularity in practices. Moreover, for there to be a convention, there must also be available alternatives to those practices, which is yet another non-intentional condition. Thus the anchors for a Lewisian convention are a mix of facts of type (A4) and (A7).

Other accounts of convention go further, challenging even Lewis's analysis as excessively intellectualist. Burge 1975, for instance, denies both that conventions are solutions to coordination problems, and that participants in a convention must have common knowledge of the convention as a solution. Burge did not provide an alternative analysis, which goes some way

${ }^{26}$ Plato ascribes this view to Hermogenes in Cratylus 384d, and Aristotle advances a similar view in De Interp. 16b19. Pufendorf 1673, Book I, Ch. 10, distinguishes tacit from explicit agreement about conventions.

${ }^{27}$ Hume 1740/1978, pp. 489-90. 
to explain why his criticisms have not been taken up by many theorists of convention. However, if the criticisms are correct, and if constitutive rules are conventions, then even facts of type (A5) are unnecessary for grounding constitutive rules.

There is little discussion in the literature on institutional facts on whether the conditions for anchoring constitutive rules must be more stringent than those for anchoring a convention. Searle argues that not all conventions are constitutive rules. He says, for instance, that it is a convention of chess that the pawn is smaller than the king, but this is not a constitutive rule. ${ }^{28}$ While this is surely correct, it does not show that constitutive rules have more stringent anchoring requirements (in the sense of (A1)-(A7)) than conventions do.

To cast doubt on the centrality of intentions in anchoring institutional facts, I will suggest that constitutive rules for social entities can be less demanding to put in place than conventions are. ${ }^{29}$ As I mentioned above, it is always a problem for the theorist of artifacts, institutional facts, and so on, to delineate just which entities ought to be included in these categories. It is all too easy to take 'artifact' or 'institutional fact' to have implicitly stipulated meanings, so that anything that is not intentionally grounded does not count as an artifact, or anything that is not anchored in collective acceptance does not count as an institutional fact. At the end of the day, though, our aim in social ontology is to characterize real phenomena, such as money, universities, screwdrivers, and boats. If some sort of money fails to be anchored in collective acceptance, I am inclined to conclude that collective

\footnotetext{
${ }^{28}$ Searle 1995, p. 28. Searle also discusses this in Smith and Searle 2003, p. 208.

${ }^{29}$ It is always an option for the convention-theorist to weaken the conditions on what counts as a convention. Millikan, for instance, proposes a rather weak set of conditions, where attitudes are not required at all for a convention to be in place. If hers is the correct analysis of convention, and if constitutive rules are conventions in this sense, then intentions are even more unnecessary for grounding constitutive rules than I am arguing here. I have criticized aspects of her theory in Epstein 2006.
} 
acceptance is not required for anchoring institutional entities, not that money thereby fails to count as an institutional entity.

Searle, in sentence (1), gives a toy constitutive rule for dollars. It is obvious that it is a toy, since the vast bulk of dollars are not in the form of printed currency. Even if (1) captured one set of sufficient conditions for an entity to be a dollar, there must be many other sets of sufficient conditions as well. My bank does not hold my deposits in paper bills. Instead, it records my deposits, and lends out a multiple of its deposit base to other accountholders, money which they hold and deposit in various ways. Money is created by banks, each of which has different ways of recording assets and liabilities. If we are to follow Searle's model for the constitutive rules for money, where the X-term gives the conditions on the substrate for counting as money, then we must have an enormous number of constitutive rules, since each bank has its own kind of substrate. They use different kinds of bank notes, ledger books, and so on. There are at least as many substrates as there are banking corporations, probably far more.

Barry Smith has criticized Searle on this point, in response to which Searle has modified his views. ${ }^{30}$ Smith argues that electronic money - i.e., records on computer disks - is not actually money, but representations of money. Bowing to this criticism, Searle has eliminated reference to an Xterm or substrate altogether for institutional objects like corporations and electronic money. Instead, he asserts that for such entities, we collectively accept that certain agents (e.g., bankers) have certain deontic powers directly, rather than having these powers assigned to a substrate. ${ }^{31}$ This is meant to obviate the problem of the "X-conditions" for corporations, electronic money, and so on.

It is not clear that this strategy is headed in the right direction. First, it is an error to suppose that these issues arise only for money when it is electronic. Long before the advent of electronic money, the amount of money

\footnotetext{
${ }^{30}$ Smith 2003; Smith and Searle 2003.

${ }^{31}$ Searle 2010, pp. 20-22, 101-102.
} 
in circulation was but a small fraction of the money in existence. ${ }^{32}$ If Searle must concede Smith's point about electronic money, it is not clear that his constitutive rule (1) is a template for any kind of real money. It is also troubling to remove the substrate entirely from the constitutive rule, since there surely has to be some substrate or record, in virtue of which a bank counts as having a certain number of dollars in its accounts. ${ }^{33}$

My present aim, however, is not to rectify either of Searle's accounts, but only to point out that we are at present far from a satisfactory treatment of the substrates or "X-terms" of constitutive rules for institutional entities like money. It is not clear - even to experts like us - which constitutive rule the community at large is taken to accept.

Moreover, the X-term turns out to be the very least of our problems, if we want to move from a toy constitutive rule for money to an adequate one. As for the function of money, there is no agreement in the economic literature even as to the basics. Any elementary textbook will tell you that the functions of money are to be a standard of value, a medium of exchange, a store of value, and a mechanism for future payments. This statement is useful for helping students think about money quite generically, and may even go a large part of the way toward explaining a social institution that existed among grain-traders in ancient Egypt. But it does little to illuminate the nature of

\footnotetext{
${ }^{32}$ It is not clear which of the various measures economists use for the quantity of money should be identified as the number of dollars outstanding - economists are likely to use "M1", which consists of notes and coins, bank reserves, traveler's checks, demand deposits, and other checkable deposits. Or they may use the "monetary base" or "total currency," which consists only of notes, coins, and bank reserves. For none of these does electronic money have anything to do with it: these measures were in place long before electronic money, and it would be easy to have a dollar-based economy with only checks - no notes, coins, or electronics.

${ }^{33}$ It is also troubling that Searle feels the need to extend this new account to institutional entities like corporations. It seems likely that if this is necessary, then other institutional entities, such as restaurants, universities, churches, nations, and so on, will be subject to the same considerations.
} 
contemporary money. ${ }^{34}$ Most economists agree that the key to the nature of contemporary money is tied to the functions of the banking sector, but they disagree on what the primary functions of that sector are. Some economists argue that the key role of banks is as intermediaries for taking on and matching risk, while others argue that their key function is to aggregate the gathering of information about firms in the economy. Corresponding to each of these functions is a different functional understanding of credit instruments, in which money is one role-player. ${ }^{35}$

Petri Ylikoski and Pekka Mäkelä have argued against collective acceptance accounts of institutions with examples that suggest that a wide range of beliefs about money, including non-collective beliefs and false beliefs, can suffice for maintaining the institution and practices of money. They argue, for instance, that the institution can be maintained if all members of a community believe that the monetary value of coins is a natural property of coins. ${ }^{36}$ This is a serious challenge to the collective acceptance theorist, who must show that such systems are not possible, or that there is good reason not to count them as institutions.

Inasmuch as our aim is gain insight into the requirements for anchoring actual institutions, however, it is not clear how instructive it is to debate the possibility and classification of highly stylized and simplified institutions. Above I suggested that the constitutive rules for dollars are enormously more complicated than those that show up in Searle's toy models. Even the toy models are beyond the ken of most users of money - it is easy to explain the

${ }^{34}$ Moreover, plenty of commonplaces about the functions of money are false. For instance, it is widely held that for an instrument to be money, it must be legal tender for future payments. There are many forms of money, however, for which this is not true (e.g. money issued by individual banks in Brazil). And even for dollars, however, there is a spate of exceptions to bills (especially large ones) being legal tender, both in law and in practice.

${ }^{35}$ For instance: Diamond 1984; He et al. 2008; Kahn et al. 2005; Kiyotaki and Moore 2001; Kiyotaki and Wright 1993; Kocherlakota 1998.

${ }^{36}$ Ylikoski and Mäkelä 2002, pp. 470-73. 
role of money as a medium of exchange and a store of value, but not so easy to explain mechanisms of future payments.

In Raimo Tuomela's discussion of the requirements for collective acceptance, he recognizes that not all members of an institution typically have an understanding of the constitutive rules for the institution. He therefore distinguishes "structured" from "egalitarian” collectives. In Tuomela's structured collective, only the "operative” members need to collectively accept the constitutive rules. ${ }^{37}$ This may appear to be a route for rescuing collective acceptance theories - i.e., restricting the acceptance requirement only to a privileged subset of community members.

For contemporary money, however, even this weaker demand is not satisfied. In giving an account of the anchoring of contemporary money or some other institution, we are not asking for the anchors of some money-like institution, nor of an ancient or primitive or stylized institution. We are interested in the anchoring of our institution. Economists have developed dozens of models of systems that have some money-like characteristics. But there is little sign of agreement among monetary theorists, to say nothing of monetary bureaucrats, on either the X-term or the Y-term of the constitutive rules for our actual institution of money. Tuomela aims to explicate and justify the slogan "what is money is not money unless it is taken to be money," 38 but it is unlikely that even a weak interpretation of the slogan can survive. ${ }^{39}$ It is probably correct that the anchors for the constitutive rules for money involve some variety of attitudes towards monetary substrates, and very likely that they involve at least some attitudes. However, to demand the collective acceptance of a constitutive rule or even an attitude towards the

\footnotetext{
${ }^{37}$ Tuomela 2000; Tuomela 2003, p. 125; Tuomela 2007, p. 198.

${ }^{38}$ Tuomela 2007, p. 198.

${ }^{39}$ If we take it as an ordinary counterfactual, of course, it is a statement about grounds as opposed to anchors, and is straightforwardly false. But if we are to be all charitable, it should be taken to be a counterfactual claim about anchoring.
} 
regularities of our monetary practices, whatever they are, is to insist on a good deal more.

This situation is common. At least since Malinowski in the 1920, sociologists and anthropologists have investigated social functions that are opaque to all the members of a society. Kinship structures, for instance, have been a staple of anthropological theory for generations. To cite a recent example, using both empirical and agent-based modeling techniques, Bearman et al. 2004 examined sexual selection characteristics among adolescents in a U.S. high school. They found that a set of implicit taboos are in place in sexual partner selection, taboos that are explainable in a number of ways but that required a sophisticated theoretical background on the part of the investigators even to articulate. A fortiori, these taboos were not even conceptualized among the high-schoolers. This example is not unusual; it is a rather pedestrian case among those we might find in the sociology or anthropology literature.

Some theorists seem to have been misled, in theorizing about the anchors for constitutive rules, by the assumption that any constitutive rule involves the assignment of a status to material objects. A constitutive rule is simply a “principle of generation” (to use Walton's term) for instances of a property, giving sufficient conditions for the property to be instantiated. As such, we should expect that they can be anchored in heterogeneous ways, whether by the existence of a reproductively established family à la Millikan, or by the existence of a homeostatic property cluster à la Boyd, or by a Lewisian convention, or perhaps even by an accidental regularity à la Hume.

To be sure, a distinction should be made between the properties that count as "social" and those that do not. But it seems likely that those standards are low - all that is needed is a little social salt added to the generative stew. Many people seem also to assume that there must be a bright red line between institutions that carry norms, or that have powers (deontic or otherwise), and those social entities that do not. And that the endowment of these norms or powers requires collective acceptance, which in turn is taken to justify the collective acceptance story for true or "standard" social institutions. This is 
clearly a larger topic than can be addressed here. But I am suspicious of both parts of this claim - that there is any clean division between institutions that carry norms of some sort and those that do not, and that collective acceptance is a special way of endowing such norms. Collective acceptance may be an essential element in certain theories of political legitimacy. But it is hard to imagine that the social institutions that pervade actual societies as they are, societies made up by mortals like us who already have enough on our minds, would have no normative force unless the character of institutions were, as Tuomela says, "all for one and one for all."

All this is not to say that human intentions, individual and collective, are irrelevant to the theory of social facts and objects. However, the claim that constitutive rules for social institutional facts can only be anchored in collective acceptance is highly dubious. And the claim that institutional facts have intentional grounds is flatly mistaken. 


\section{References}

Baker, L. R. (2004). The Ontology of Artifacts. Philosophical Explorations, 7(2), 99-111.

Bearman, P. S., J. Moody and K. Stovel (2004). Chains of Affection: The structure of adolescent romantic and sexual networks. American Journal of Sociology, 110(1), 44-91.

Burge, T. (1975). On Knowledge and Convention. Philosophical Review, 84(2), 249-55.

Correia, F. (2005). Existential Dependence and Cognate Notions. Munich: Philosophia Verlag.

Diamond, P. A. (1984). Money in Search Equilibrium. Econometrica, 52, 120.

Epstein, B. (2006). Review of Language: A biological model by Ruth Millikan. Notre Dame Philosophical Reviews. http://ndpr.nd.edu/news/25029-language-a-biological-model/. Accessed 10 January 2012.

Fine, K. (2001). The Question of Realism. Philosopher's Imprint, 1(1), 1-30.

Godfrey-Smith, P. (1996). Complexity and the Function of Mind in Nature. Cambridge: Cambridge University Press.

He, P., L. Huang and R. Wright (2008). Money, Banking, and Monetary Policy. Journal of Monetary Economics, 55, 1013-24.

Hindriks, F. (2008). The Status Account of Corporate Agents. In H. B. Schmid, K. Schulte-Ostermann and N. Psarros (Eds.), Concepts of Sharedness: Essays on collective intentionality (pp. 119-44). Frankfurt: Ontos.

Hume, D. (1740/1978). A Treatise of Human Nature. New York: Oxford University Press. 
Kahn, C., J. McAndrews and W. Roberds (2005). Money is Privacy. International Economic Review, 46, 377-404.

Kiyotaki, N. and J. Moore (2001). Evil is the Root of All Money. Clarendon Lecture.

Kiyotaki, N. and R. Wright (1993). A Search-Theoretic Approach to Monetary Economics. The American Economic Review, 83(1), 63-77.

Kocherlakota, N. (1998). Money is Memory. Journal of Economic Theory, 81, 232-51.

Lewis, D. K. (1969). Convention: A philosophical study. Cambridge, MA: Harvard University Press.

Millikan, R. G. (1984). Language, Thought, and Other Biological Categories: New Foundations for Realism. Cambridge: MIT Press.

_ (1999). Historical Kinds and the "Special Sciences". Philosophical Studies, 95, 45-65.

Pufendorf, S. (1673). On the Duty of Man and Citizen According to Natural Law.

Searle, J. R. (1995). The Construction of Social Reality. New York: Free Press.

(2010). Making the Social World: The structure of human civilization. Oxford: Oxford University Press.

Smith, B. (2003). John Searle: From speech acts to social reality. In B. Smith (Ed.), John Searle. Cambridge: Cambridge University Press.

Smith, B. and J. R. Searle (2003). The Construction of Social Reality: An exchange. American Journal of Economics and Sociology, 62(1), 285309.

Thomasson, A. (2003). Foundations for a Social Ontology. ProtoSociology, 18-19, 269-90. 
(2007). Artifacts and Human Concepts. In E. Margolis and S. Laurence (Eds.), Creations of the Mind: Theories of artifacts and their representation. Oxford: Oxford University Press.

Tuomela, R. (2000). Belief Versus Acceptance. Philosophical Explorations, 2, 122-37.

- (2002). The Philosophy of Social Practices: A collective acceptance view. Cambridge: Cambridge University Press.

- (2003). Collective Acceptance, Social Institutions, and Social Reality. American Journal of Economics and Sociology, 62, 123-65.

- (2007). The Philosophy of Sociality: The shared point of view. Oxford: Oxford University Press.

Walton, K. (1990). Mimesis as Make-Believe: On the foundations of the representational arts. Cambridge, MA: Harvard University Press.

Ylikoski, P. and P. Mäkelä (2002). We-attitudes and Social Institutions. In G. Meggle (Ed.), Social Facts and Collective Intentionality (pp. 459-74). Frankfurt: Dr. Hänsel-Hohenhausen AG. 